\title{
RIGOR, RELEVÂNCIA E DESAFIOS DA ACADEMIA EM ADMINISTRAÇÃO: TENSÕES ENTRE PESQUISA E FORMAÇÃO PROFISSIONAL
}

\author{
RIGOR, RELEVANCE AND CHALLENGES IN ADMINISTRATION: \\ TENSIONS BETWEEN RESEARCH AND PROFESSIONAL EDUCATION \\ RIGOR, RELEVANCIA Y RETOS DE LA ACADEMIA EN ADMINISTRACIÓN: \\ TENSIONES ENTRE INVESTIGACIÓN Y FORMACIÓN PROFESIONAL
}

RESUMO

Recuperamos a trajetória do ensino e da pesquisa em administração no Brasil para discutir desafios atuais quanto à construção da relevância da produção científica. A análise da trajetória da $R A E$ revela tensões entre pesquisa e tradição da formação profissional, ou, ainda, entre rigor e relevância: de uma revista que refletiria o pensamento da FGV-EAESP, voltada à classe emergente dos administradores, carentes de conhecimento especializado e relevante, a uma ferramenta essencial ao debate e à divulgação científica, agora já no círculo acadêmico especializado. Essa inflexão caracterizou-se pela implantação progressiva de critérios e procedimentos acadêmicos e pela ênfase crescente no rigor teórico-metodológico. Porém, a questão da relevância e do impacto do conhecimento produzido sugere reflexões importantes à comunidade científica. Entre as questões que levantamos, estão: de que problemas tratamos? Como o fazemos? Quais as contribuições de nossos textos? Para quem escrevemos? Que diálogos promovemos junto a outras esferas da sociedade?

PALAVRAS-CHAVE Ensino e pesquisa em Administração, rigor, relevância, produção científica, periódicos acadêmicos.

André Ofenhejm Mascarenhas andremascar@fei.edu.br

Professor do Programa de Pós-Graduação em Administração do Centro Universitário da FEl - São Paulo - SP, Brasil

Felipe Zambaldi zambaldif@gmail.com

Professor do Programa de Pós-Graduação em Administração do Centro Universitário da FEl e Professor da Escola

de Administração de Empresas de São Paulo, Fundação Getulio Vargas - São Paulo - SP, Brasil

Edmilson Alves de Moraes edmilson@fei.edu.br

Professor do Programa de Pós-Graduação em Administração do Centro Universitário da FEI - São Paulo - SP, Brasil

Abstract We recover the educational and research trajectory of the administration field in Brazil to discuss current challenges regarding the relevance of scholarly production. The analysis of RAE's history reveals tensions between research and the tradition of professional training, or even between rigor and relevance: from a journal which reflected the thinking of FGV-EAESP, focused on the emerging class of managers, who lacked specialized and relevant knowledge, to an essential debate forum and scientific publication, now for specialized academic circles. This change was characterized by the progressive introduction of academic criteria and procedures and a growing emphasis on theoretical and methodological rigor. However, the issue of the relevance and impact of the knowledge created suggests important questions to the scientific community. Among the issues we raise there are the following: what problems do we address? How do we do it? What are the contributions of our texts? For whom do we write? Which dialogues with other spheres of society do we promote?

keywords Education and research in Administration, rigor, relevance, scholarly production, scientific journals.

Resumen Recuperamos la trayectoria de la enseñanza y de la investigación en administración en Brasil para discutir los desafíos actuales en relación con la construcción de la relevancia de la producción científica. El análisis de la trayectoria de la RAE revela tensiones entre investigación y tradición de formación profesional o, incluso, entre el rigor y la relevancia: la RAE pasó de una revista que refleja el pensamiento de la FGV-EAESP, focalizada en la emergente clase de los administradores, carentes de conocimiento especializado y relevante, a una herramienta esencial para el debate y la publicación científica, ahora en los círculos académicos especializados. Esta inflexión se ha caracterizado por la introducción progresiva de criterios y procedimientos académicos y por el creciente énfasis en el rigor teórico y metodológico. Sin embargo, la cuestión de la relevancia y del impacto del conocimiento producido sugiere consideraciones importantes para la comunidad cientifica. Entre las cuestiones que planteamos están las siguientes: ¿qué problemas tratamos? ¿Cómo 10 hacemos? ¿Cuáles son las contribuciones de nuestros textos? ¿Para quién escribimos? ¿Que diálogos promovemos con otras esferas de la sociedad?

Palabras clave Enseñanza e investigación en Administración, rigor, relevancia, producción científica, revistas científicas. 


\section{INTRODUÇÃo}

Em 2011, celebramos dois marcos importantes na história do ensino e da pesquisa em administração no Brasil. O primeiro são os 70 anos da criação do primeiro curso destinado à formação de administradores, a Escola Superior de Administração de Negócios (ESAN), em São Paulo. O segundo são os 50 anos da primeira edição do periódico científico mais tradicional em administração, a Revista de Administração de Empresas ( $R A E$ ), publicada e mantida pela FGV-EAESP. Neste artigo, recuperamos as trajetórias do ensino e da pesquisa em administração no Brasil para discutir desafios atuais relacionados à construção da relevância de nossa produção científica. Criados originalmente para fomentar e complementar os programas de formação profissional, os periódicos das escolas de administração tornaram-se, mais recentemente, ferramentas essenciais ao debate e à divulgação da produção acadêmica dos programas de pós-graduação. Argumentamos que essa evolução impôs tensões entre a pesquisa acadêmica e a tradição da formação profissional, ou, ainda, entre rigor e relevância.

Esse processo, que impôs à comunidade de leitores a ênfase no rigor teórico-metodológico, permite-nos reconhecer a trajetória de amadurecimento e consolidação de nossa área acadêmica como campo de conhecimento, por meio da evolução de nossos periódicos, que se firmaram como arenas do debate científico. Contudo, ao longo desse processo, restringimos nosso alcance e relevância à comunidade de pesquisadores da área. Após o crescimento das submissões na última década, reconstruir a relevância de nossa produção científica tornou-se um objetivo legítimo, e as questões que agora se colocam são: de quais problemas tratamos? Como o fazemos? Quais as contribuições de nossos textos? Para quem escrevemos? Quais são os diálogos que promovemos junto a outras esferas da sociedade? Diante dessas questões, arriscamos uma provocação: devemos avançar no debate sobre o impacto de nossa produção.

Com base na definição de rigor e relevância da produção científica, sugerimos a existência de uma tensão entre a vocação do ensino em administração no Brasil, que vem suprindo necessidades inerentes ao processo do desenvolvimento brasileiro, e a tendência por privilegiar o rigor científico da produção bibliográfica das instituições de ensino e pesquisa, em detrimento da relevância. Para ilustrar essa tendência, caracterizamos a evolução da formação de profissionais e pesquisadores em administração no Brasil, e do fomento à produção de conhecimento, interpretando a trajetória da $R A E$, para então propor reflexões quanto à relevância de nossa produção.

\section{O QUE É RELEVÂNCIA? O QUE É RIGOR?}

Apesar de seu uso corrente no debate acadêmico, a ideia de relevância do trabalho científico não vem sendo definida com precisão por abarcar ambiguidade e complexidade. Por exemplo, Nicolai e Seidl (2010) exploram a noção de relevância prática, ou a diferença que o conhecimento faz à prática, podendo assumir a forma de relevância instrumental (quando o conhecimento se presta à aplicação prática direta), conceitual (quando o conhecimento revela entendimentos novos com base nos quais se pode repensar a realidade) ou legitimadora (quando o conhecimento legitima aspectos da realidade). À relevância prática, acrescentamos a noção de relevância teórico-metodológica, quando o conhecimento prova-se pertinente à evolução de nossos entendimentos ou procedimentos científicos. De modo geral, relevância diz respeito ao consenso social em torno da importância e pertinência dos problemas tratados, que devem ser dignos de atenção pela comunidade, e para os quais a pesquisa deve trazer novos conhecimentos capazes de esclarecê-los ou de redefini-los (VASCONCELOS, 2009).

Outro aspecto do trabalho científico é o rigor. O rigor implica a construção teórica e conceitual cuidadosa e a observância a estritos ditames metodológicos. A noção de rigor de um trabalho acadêmico também abarca complexidades, pois está submetida a convenções específicas nas comunidades científicas. Em geral, o reconhecimento do rigor de um trabalho acadêmico depende da apreciação da qualidade e da pertinência do conjunto de decisões sobre métodos, abrangendo a consistência das escolhas teórico-metodológicas. O rigor de um texto científico é uma qualidade cujo reconhecimento está submetido a convenções acordadas nas comunidades científicas. Por exemplo, em etnografia, o rigor estaria associado à capacidade de um texto convencer o leitor experiente, abrangendo aspectos como autenticidade, plausibilidade e criticidade (GOLDEN-BIDDLE e LOCKE, 1993). Em estudos de múltiplos casos, o rigor metodológico diz respeito 
à capacidade de o estudo permitir a construção de teoria por meio da replicação entre casos (EISENHARDT, 1991). Em especial, a estrutura geral do trabalho, articulada pela tríade objetivos - teoria - metodologia, revela a visão teórico-metodológica adotada, enquanto a seção de metodologia especifica as decisões tomadas e executadas, bem como as justifica no contexto geral da pesquisa.

Argumentamos que nossas práticas científicas vêm privilegiando o rigor, em detrimento da relevância. Contudo, a fundamentação de um trabalho científico ao qual se atribui valor social significativo abrange a relevância e o rigor (VASCONCELOS, 2009). Apelos por repensarmos nossos comprometimentos em ciência com vistas à relevância já vêm sendo feitos (MATTOS, 2008; VASCONCELOS, 2009). Para Mattos (2008), por exemplo, um artigo científico seria relevante dependendo de sua capacidade de (1) originar novos entendimentos, (2) atrair a atenção de audiências na comunidade ou, ainda, (3) surpreender, criticar, ou contestar suposições anteriores. Produzir ciência com excelência dependeria da construção do rigor e da relevância do texto científico, permitindo o impacto na comunidade, sendo inclusive condição para a publicação em periódicos de grande prestígio. Estaríamos comprometidos com tais objetivos? Como levá-los a cabo?

O debate sobre a relevância da pesquisa em administração é antigo e complexo, e reflete a dicotomia clássica entre teoria e prática, diz respeito à natureza do conhecimento que produzimos e emerge das maneiras distintas com que acadêmicos e praticantes produzem e consomem conhecimento. Esse debate vem atraindo a atenção de pesquisadores formadores de opinião, tais como editores de periódicos prestigiosos, preocupados com a falta de valor social de nossa pesquisa, e para quem a lacuna entre a pesquisa e a prática é grande, sugerindo impactos desejáveis em políticas editoriais e agendas de pesquisa (RYNES, 2007; RYNES, BARTUNEK, DAFT, 2001). Por exemplo, em editorial do Journal of Management Studies, Clark, Floyd e Wright (2006) convidam os autores à reflexão profunda das implicações de suas ideias ao domínio cotidiano da administração, apesar de reconhecerem ser a comunidade acadêmica seu principal público.

Apelos por mais ênfase à relevância da pesquisa em administração não são fenômeno nosso. Na realidade, esse debate está no centro dos questionamentos à identidade das escolas de negócios no mundo anglo-saxão (HUFF e HUFF, 2001; PFEFFER e FONG, 2002; MINTZBERG, 2004) e vem gerando discussões sobre nossos modelos de produção do conhecimento científico (GIBBONS e outros, 1994; SWAN e outros, 2010), sobre como tal conhecimento se preza ao uso na prática (NICOLAI e SEIDL, 2010), sobre a natureza e a dinâmica das interações entre acadêmicos e praticantes (BEECH, MACINTOSH, MACLEAN, 2010; KNIGHTS e SCARBROUGH, 2010), entre diversos outros tópicos inter-relacionados. Desafios ao debate incluem a busca de definições adequadas aos conceitos de conhecimento, teoria, rigor e relevância, e às suas relações sistemáticas com ação e prática, além de questões éticas e dificuldades teóricas e empíricas atreladas ao desenvolvimento de teorias sobre a geração, transferência e uso do conhecimento (JARZABKOWSKI, MOHRMAN, SCHERER, 2010, p. 1191).

\section{PRODUÇÃO E DISSEMINAÇÃO dE CONHECIMENTO EM ADMINISTRAÇÃO NO BRASIL: TENSÕES ENTRE A PESQUISA E A TRADIÇÃo DA FORMAÇÃo PROFISSIONAL OU, AINDA, ENTRE RIGOR E RELEVÂNCIA}

A discussão sobre a relevância da produção acadêmica em administração faz-se presente, aqui e acolá, e suas críticas encontram pertinência em nossa comunidade. A última década viu consolidar-se o debate sobre a qualidade de nossa produção científica. No Brasil, o debate acerca da relevância da produção em administração revela a existência de desafios que merecem reflexão. De modo consensual, o recente aumento quantitativo da pesquisa não estaria relacionado à maior qualidade (TONELLI e outros, 2003). No final da década de 1990, Bertero, Caldas e Wood Jr. (1999) resumiram as análises de autores pioneiros no debate sobre nossa produção acadêmica, sugerindo que nossa produção seria pouco relevante e rigorosa. Mais recentemente, os mesmos autores voltaram a enfatizar suas conclusões, sugerindo fragilidade e baixa relevância da produção científica, voltada essencialmente à academia, "o que indica pouca preocupação com aplicabilidade e pouca atenção ao universo gerencialista e à problemática concreta enfrentada por administradores no interior e à frente de organizações" (BERTERO, CALDAS, WOOD JR, 2005, p. 13).

De fato, somos facilmente tentados a refletir sobre a existência de uma comunidade acadêmica fechada: 
poucos praticantes da administração frequentam $O$ Enanpad (o maior encontro para discussões de pesquisas em administração no Brasil) ou são assinantes de nossos periódicos. Poderíamos contra-argumentar dizendo que nossos textos não são escritos para tal audiência, sendo ferramentas de trabalho do pesquisador e do estudante. Contudo, o estudante de administração é o próprio praticante da administração ou, ao menos, aspira a sê-lo. Ademais, não desenvolvemos canais definitivos de diálogo em mão dupla, que promovam debates profícuos entre as comunidades e que contextualizem nossa pesquisa. Essa situação reforça concepções preconceituosas e reducionistas, muito comuns entre os praticantes, segundo as quais a pesquisa acadêmica perderia em apelo prático, tornandose mais restrita e distante do mundo real, crença que reforça dificuldades à aproximação mútua (GULATI, 2007; GHOSHAL, 2005).

Apesar das críticas também frequentes a aspectos de rigor da produção, nossa prática científica vem privilegiando-o, em detrimento do debate sobre a relevância dos artigos. Por exemplo, a relevância de um manuscrito submetido a um periódico vem sendo subjetivamente avaliada no âmbito do processo editorial (por avaliadores e editores) e objetivamente avaliada por meio de medidas como fatores de impacto, após a publicação. Apesar da importância crescente desses índices à avaliação dos docentes, nossos pareceres tendem a enfatizar o rigor de nossos trabalhos (MATTOS, 2008). Fichas de avaliação de artigos utilizadas por nossos periódicos valorizam aspectos formais (tais como adequação teoria-metodologia ou o rigor na análise de dados). Em vários periódicos, essa apreciação resumese a uma nota dada pelo avaliador, ou à escolha da opção "este trabalho contribui para o avanço do conhecimento", sem que se estimule um diálogo aprofundado sobre a contribuição do artigo ou seu potencial de impacto na comunidade. Diante dessa situação, editores-chefes teriam à sua disposição ferramental limitado para avaliar a potencial relevância dos artigos submetidos (KIRSCHBAUM e MASCARENHAS, 2009; PINHO, 2005; MATTOS, 2008).

É de interesse da comunidade de acadêmicos e de praticantes da administração refletir sobre como a produção e disseminação de conhecimento têm se colocado diante dos desafios da capacitação profissional na área ou, ainda, quais tensões têm surgido entre a produção acadêmica e a prática da administração. Tal debate faz-se pertinente porque seria a finalidade do sistema de educação superior produzir e disseminar conhecimento relevante à sociedade.
O resgate da evolução do ensino em administração no Brasil evidencia a vocação de nossas escolas de negócios para a formação profissional alinhavada às demandas da atividade econômica nacional, o que não se limita aos cursos de graduação. A proliferação de cursos de especialização, de programas de educação continuada e de mestrados profissionais também se presta a capacitar ou atualizar profissionais por meio da oferta de conteúdo em gestão. Mesmo em programas de mestrado acadêmico, é possível verificar a demanda por educação de candidatos atuantes nos diversos setores das iniciativas privadas ou da esfera pública. Eles buscam maior capacitação para promover a aproximação entre a prática empresarial e o conhecimento produzido nos limites do mundo acadêmico, sem o intuito de atuarem como pesquisadores, mas, sim, de continuarem suas carreiras como praticantes da gestão, porém com maior legitimidade e formação mais substantiva. Adicionalmente, o mestrado acadêmico tem sido, por vezes, o meio encontrado por professores do ensino superior ou aspirantes à carreira docente em nível superior para se estabelecerem e se manterem lecionando, sem o compromisso de produzir contribuições acadêmicas, mas a fim de se qualificarem para a transmissão do conhecimento demandado à formação de profissionais da gestão.

Sugerimos a existência de uma tensão entre a vocação do ensino em administração no Brasil, que vem suprindo necessidades inerentes ao processo do desenvolvimento brasileiro, e a tendência por privilegiar o rigor científico da produção bibliográfica das instituições de ensino e pesquisa, em detrimento da relevância. Para ilustrar essa tendência, caracterizamos, na próxima seção, a evolução do fomento à produção de conhecimento e da formação de profissionais e pesquisadores em administração no Brasil, interpretando a trajetória da $R A E$, para então enfatizar a discussão sobre a relevância de nossa produção.

\section{DA RELEVÂNCIA AO RIGOR: TRAJETÓRIA DA FORMAÇÃO PROFISSIONAL E DA PRODUÇÃO BIBLIOGRÁFICA NAS INSTITUIÇÕES DE ENSINO EM ADMINISTRAÇÃO NO BRASIL}

É possível delimitar duas fases da produção bibliográfica nas instituições de ensino e pesquisa em administração no Brasil, traçando um paralelo com o 
papel atribuído dentro dessas instituições aos programas de pós-graduação. Desde a fundação das primeiras escolas de negócios, a primeira fase da produção bibliográfica direcionava-se à classe emergente dos administradores brasileiros, carentes de conhecimento especializado e relevante. A partir da década de 1990, a segunda fase reflete o aprofundamento do processo normatizador que fomentava a pós-graduação para transformá-la numa rede provedora de pesquisadores.

O ensino de administração no país está associado às demandas advindas do desenvolvimento industrial brasileiro, que toma impulso definitivo após a Revolução de 1930, quando se estabeleceu as bases de um pacto político que privilegiou o desenvolvimento industrial (BRESSER-PEREIRA, 1994). A década de 1930 foi palco de mudanças estruturais em nosso país, quando o setor industrial passou a substituir o setor agrícola como principal motor da economia (BOUZAN, 1966), mudando a estrutura social, com o desenvolvimento de novas classes sociais como a burguesia industrial e o proletariado urbano. Neste contexto de acelerado desenvolvimento surgem as primeiras escolas de comércio e de economia do Brasil (SILVA, 1971). Estas mudanças culminam na década de 1940 com um crescimento acelerado da demanda interna, que representou grande oportunidade de investimento para empresários brasileiros. Simultaneamente, por conta da Segunda Grande Guerra, os países desenvolvidos reduziram suas exportações sensivelmente, induzindo o aumento da produção industrial brasileira (BRESSER-PEREIRA, 1994). Neste período, a gestão das empresas ficava na maior parte das vezes por conta de profissionais como engenheiros e químicos, que não dominavam as modernas técnicas administrativas que então se disseminavam nos Estados Unidos e Europa (FREITAS, 1998).

A demanda por profissionais capacitados em técnicas especializadas de gestão marca o surgimento das primeiras escolas de Administração brasileiras, que datam justamente das décadas de 1940 e 1950. A pioneira foi a ESAN, criada em 1941 (atualmente FEIAdministração), à qual seguiu a Faculdade de Ciências Econômicas e Administrativas (FCEA), criada em 1946 (atualmente FEA-USP). O modelo da Graduate School of Business Administration da Universidade de Harvard serviu de base para a criação da ESAN, que tinha como missão formar gerentes tecnicamente preparados (SOUZA, 1980; BERTERO, 2006). A criação da FCEA da Universidade de São Paulo teve como objetivo formar quadros para o setor da administração pública e privada. Em seus primeiros 20 anos, foram ministrados apenas os cursos de Ciências Econômicas e Administrativas e de Ciências Contábeis e Atuariais (FREITAS, 1998), pois, na época, a Administração ainda não havia se emancipado como opção para formação e atuação profissional especializada. Havia, à época, certa confusão entre Administração e Economia, dado que "com alguma frequência os cursos de Administração nasceram em escolas de economia" (SILVA, 1971, p. 18), sendo, muitas vezes, a Administração um departamento das escolas de ciências econômicas.

Com o fim da guerra, novas perspectivas abriramse ao Brasil, como a redução de barreiras para importação de equipamentos, a consolidação da indústria leve de consumo e o início da fabricação de bens de consumo mais complexos, como eletrodomésticos. O decênio pós-guerra foi, portanto, importante para o desenvolvimento industrial (BRESSER-PEREIRA, 1994). Nesse período, foram criados mais dois importantes cursos de administração no Brasil. Em 1952, iniciouse, no Rio de Janeiro, o curso de Administração Pública oferecido pela Escola Brasileira de Administração Pública (EBAP) da Fundação Getulio Vargas (FGV). Em 1954, em São Paulo, o curso de Administração de Empresas passou a ser oferecido pela Escola de Administração de Empresas de São Paulo (EAESP), também da FGV. As criações da EBAP e da EAESP ocorreram em um momento histórico, em que o segundo governo de Vargas procurava conduzir uma política econômica nacionalista, baseada na criação de empresas estatais e de empresas privadas nacionais (FREITAS, 1998).

A partir da segunda metade da década de 1950, o governo do Presidente Juscelino Kubitschek criou novos estímulos a investimentos privados nacionais e estrangeiros, consolidando uma política nacional industrializante. A estratégia de desenvolvimento passou a privilegiar grandes unidades produtivas, induzindo o crescimento acelerado da participação de grandes empresas, demandando maior emprego de técnicas administrativas (BOUZAN, 1966; BRESSER-PEREIRA, 1994). Por conta da necessidade de profissionais com treinamento específico, as grandes empresas passaram a profissionalizar seus quadros, contratando administradores formados pelo então recém-criado sistema escolar especializado. O Brasil, que já atingira relativo grau de autossuficiência global em sua industrialização, iniciou, então, sua trajetória para tornar-se independente na produção de equipamentos (BRESSERPEREIRA, 1994).

Na primeira metade da década de 1960, consolidou-se o desenvolvimento da indústria automobilística, da indústria de máquinas-ferramentas, da indústria 
metalúrgica e de algumas indústrias básicas. A criação do curso de graduação em administração da FEA-USP, em 1964, coincidiu com esse momento, em que grandes empresas estrangeiras consolidaram-se no mercado interno brasileiro (FREITAS, 1998). Em especial, a tendência de profissionalização do administrador acentuou-se com a regulamentação dessa profissão pela Lei n. 4.796, de 9 de setembro de 1965. A demanda por profissionais que dominassem métodos modernos de administração levou ao surgimento de escolas de administração em todo o país. Também na década de 1960, com a promulgação da Lei n. 4.024/1961 e do parecer CFE n. 977, de 3 de dezembro de 1965 que estabeleceram a distinção entre a pós-graduação stricto sensu e lato sensu (ALMEIDA JUNIOR e outros, 2005), surgiram os primeiros cursos de mestrado em administração no Brasil, como os da FEA-USP (1964) e da FGV-EAESP (1965).

Nas décadas de 1970 e 1980, o crescimento do número de administradores profissionais de nível médio relacionava-se fundamentalmente às técnicas de produção em massa, ao aumento da produtividade, à aceleração da automação e ao fortalecimento de grandes empresas e organizações estatais (BRESSER-PEREIRA, 1994). Até a primeira metade da década de 1990 , tornou-se premente a necessidade de administradores de nível médio com funções essencialmente de coordenação e assessoria em setores como os de relações industriais, controle de produção, qualidade e estoque, compras, transportes, pesquisa e desenvolvimento, manutenção, planejamento financeiro, contabilidade e controle de custos (BRESSER-PEREIRA, 1994). Na década de 1970, a FGV passou a ministrar um programa de doutorado, consolidando-se como um centro formador de professores para outras instituições que vivenciavam grande expansão dos cursos de administração (FREITAS, 1998).

É esse contexto que demarca a primeira fase da produção bibliográfica nas instituições de ensino em administração no Brasil. Essa fase abrange a fundação das escolas e cursos brasileiros de administração e passa pela criação de programas de mestrado e doutorado a partir da década de 1960. A produção bibliográfica desse período esteve mais associada à divulgação do conhecimento profissional ministrado nas escolas que mantinham e publicavam periódicos próprios, como foram os casos da RAE da FGV-EAESP; da Revista de Administração da USP (Rausp); e da Revista de Administração Pública $(R A P)$ da FGV-EBAPE. Ao longo destas décadas, a relevância da produção bibliográfica em adminis- tração refere-se, principalmente, à pertinência dos textos diante das necessidades de capacitação de uma classe profissional em ascensão em uma sociedade em desenvolvimento.

Posteriormente, já na década de 1990, agências como CAPES e CNPq consolidaram sua atuação de normatização da pós-graduação como predominantemente orientada para a produção e disseminação de pesquisa e formação de pesquisadores. Até então, o papel de normatização dessas agências junto à pósgraduação estava mais associado ao fomento e regulamentação de programas que capacitassem docentes para o ensino superior.

\section{ESTUDO DO CASO RAE}

Um caso especial que ilustra a evolução das publicações da área é o da RAE, criada em 1961 como instrumento de promoção do curso de administração da FGV-EAESP, que havia se iniciado em 1954 (GVEXECUTIVO, 2011). Nesta seção, recuperamos a trajetória da $R A E$ para mostrar como esse processo caracterizou-se pela implantação progressiva de critérios e procedimentos acadêmicos e científicos, e pela ênfase crescente no rigor teórico-metodológico, com implicações à percepção de relevância.

Aproveitando a comemoração de 50 anos da revista, privilegiamos o acervo da $R A E$ para a análise que propomos, primeiramente, por se tratar do periódico com o maior impacto na área (MACHADO-DA-SILVA e outros, 2008). Adicionalmente, a RAE é o mais antigo periódico de circulação ininterrupta em sua área, com sua primeira edição publicada em 1961 (embora a Rausp date de 1947, sua publicação enfrentou interrupções nas décadas de 1950 e 1960). As mudanças vivenciadas pela academia brasileira em administração desde a década de 1990 ocorreram quando a $R A E$ já contava com acúmulo de textos ao longo de mais de três décadas, sendo possível identificar a trajetória de transformações de seu conteúdo.

A análise que apresentamos sobre a trajetória da $R A E$ iniciou-se com a listagem das referências dos textos publicados desde seu primeiro volume, em 1961, incluindo autoria, título, dados da publicação e palavras-chave. Os artigos incluídos foram os teórico-empíricos, puramente teóricos ou ensaísticos. Resenhas, indicações bibliográficas, entrevistas e documentos especiais não foram analisados, por não se constituírem produção científica cuja análise foi proposta neste trabalho. Um primeiro conjunto 
de procedimentos teve como objetivo evidenciar a trajetória de áreas temáticas, autores e assuntos publicados pela $R A E$. Definiu-se, em primeiro lugar, um conjunto inicial de categorias, replicando-se as áreas temáticas definidas atualmente pela Anpad. Todo o acervo da revista foi, então, classificado por meio da análise textual dos títulos e palavras-chave, quando disponíveis, buscando identificar a aderência dos textos às categorias temáticas. Esses procedimentos também permitiram a identificação de assuntos e autores reincidentes. O processo foi operacionalizado por meio de uma planilha eletrônica e exigiu ajustes contínuos no conjunto de categorias temáticas e assuntos identificados ao longo de diversas rodadas de classificação envolvendo os três pesquisadoresautores e quatro assistentes de pesquisa. Construímos, então, listas com assuntos e autores reincidentes e os organizamos por décadas. Tal critério justificou-se por seu caráter didático, e também por ser consistente com a trajetória de mudanças estruturais pelas quais a revista passou, conforme relatos de exeditores obtidos em uma entrevista e em documentos publicados. Um segundo conjunto de procedimentos teve como objetivo revelar a evolução de elementos estruturais dos trabalhos publicados (existência de características de redação e formato de artigos científicos, estilo de escrita, uso de métodos, comprometimentos do texto). Essa etapa implicou acesso ao texto integral de, aproximadamente, 30\% do acervo, analisado qualitativamente pelos pesquisadoresautores, de modo que, em primeiro lugar, se dirimissem dúvidas quanto à classificação temática do texto (nem todos os títulos e assuntos, em especial nas primeiras décadas da revista, puderam ser facilmente classificados) e, em segundo lugar, se construísse um conjunto de registros e observações quanto às características citadas, também organizados por décadas. A construção do caso RAE fundamentou-se nos resultados obtidos com ambos os conjuntos de procedimentos, implicando, também, a verificação da consistência desses resultados diante de documentos sobre a trajetória da revista. Esse processo analítico aconteceu ao longo dos meses de fevereiro, março e abril de 2011, e seu resultado apresenta-se a seguir.

\section{RAE EM SEUS 50 ANOS}

Desde seu lançamento, a política editorial da $R A E$ alinhava-se às necessidades de uma classe profissional emergente, privilegiando conteúdos profissionais e complementando os cursos da EAESP. A revista foi lançada como um projeto editorial representando o pensamento da EAESP. Segundo o Prof. João Carlos Hopp, membro do corpo redatorial da revista por ocasião de seu lançamento, "sempre tentamos fazer a $R A E$ atingir os leitores de todas as áreas; queríamos atingir o maior número de pessoas interessadas e olhar a Administração como um todo, mostrar ao administrador como ele poderia administrar e que ele poderia colocar a empresa dele numa posição atual" (VALENTE e SERAFIM, 2006, p. 106-107). Para o Prof. Hopp, empresas apoiadoras da EAESP contribuíram com a difusão da revista na época, pois seus "diretores e presidentes começaram a incentivar seus funcionários a lerem artigos da $R A E$, e eles eram efetivamente lidos" (VALENTE e SERAFIM, 2006, p. 107).

A década de 1960 caracterizou-se, então, pela publicação de textos fundamentais, conceituais e técnicos. Fundamentais porque eram pioneiros e versavam de maneira genérica sobre grandes conceitos, como que os introduzindo, tais como seleção de pessoal, concordatas, liquidez, planejamento econômicofinanceiro, contabilidade, relações humanas, controle orçamentário e desenvolvimento industrial, relacionando-os de maneira ensaística. Os textos formulavam ou propunham aos leitores conceitos e técnicas, com forte inclinação descritiva e prescritiva. As seções de metodologia, quando presentes, eram rudimentares. Chama à atenção a grande incidência de textos sobre a realidade brasileira, incluindo temas como subdesenvolvimento, qualificação dos administradores no Brasil, investimentos estrangeiros no Brasil, desemprego e mercado de trabalho, inflação, crédito e outros aspectos pertinentes à economia brasileira, como a indústria paulista, os balanços setoriais, o empresariado nacional, a mão de obra, os conflitos sindicais e as relações industriais. No que diz respeito ao estilo de escrita, era comum que os artigos fossem iniciados com a descrição de problemas cotidianos dos gerentes, para, então, serem apresentadas possíveis soluções na forma de técnicas. Quanto aos autores, chama a atenção a polivalência de alguns, além da tradução de autores hoje considerados clássicos, como Michel Crozier e Tom Burns.

Na década de 1970, os textos publicados na $R A E$ assumem caráter mais analítico e passam gradativamente a aprofundar temas, em especial, debates sobre desenvolvimento e subdesenvolvimento, dependência econômica, sistema bancário, sistema financeiro e aspectos da economia e história econômica brasileira. Destaque aos muitos artigos 
de economistas da FGV-EAESP, como Eduardo Matarazzo Suplicy e Luiz Carlos Bresser-Pereira. Surgem domínios temáticos mais especializados, como marketing de turismo e marketing imobiliário, ensino em administração, gestão tecnológica, gestão dos recursos naturais, agronegócio e administração hospitalar. São publicados artigos de natureza sociológica, política, demográfica e histórica, com destaque aos textos de Fernando Prestes Motta, Henrique Rattner, Carlos Osmar Bertero, Pólia Lerner Hamburguer e Raimar Richers. Progressivamente, os títulos tornam-se mais extensos e complexos, passam a conter palavras de caráter mais científico (de relações humanas para behaviorismo, de organograma para estruturalismo) e a alegar fundamentação em pesquisa ou em revisão bibliográfica.

Na década de 1980, os trabalhos em torno de temas desenvolvimentistas, como o intervencionismo e protecionismo do Estado, e os desafios enfrentados pela máquina pública, continuam bastante recorrentes na revista. A internacionalização de negócios e discussões envolvendo os desafios de empresas transnacionais são assuntos que aparecem com destaque no início da década. Temas gerenciais também seguem sua trajetória de proliferação, com ampla apresentação e discussão de ferramentas de gestão voltadas ao marketing, às finanças, às vendas, à administração da produção e à gestão de projetos. Nesse período, a revista parece assumir mais fortemente uma vocação que, futuramente, permitiria sua classificação como periódico voltado ao management. Esta expressão em inglês consagrou uma corrente de pensamento em administração orientada, desde a primeira metade do século XIX, à compreensão de questões envolvendo a mobilização de pessoas para consecução de objetivos organizacionais com embasamento científico e uso eficiente de recursos (humanos, financeiros, tecnológicos e naturais, entre outros). A tendência vocacional da $R A E$ observa-se com a introdução de assuntos em psicologia e sociologia das organizações, comportamento organizacional, gestão de recursos humanos e estratégia empresarial. O termo estratégia, inclusive, aparece em vários títulos, muitas vezes antecipando o que hoje conhecemos como abordagens econômicas da pesquisa em estratégia de empresas, com uso de conceitos da organização industrial e da economia de custos de transação, mesmo sem assumir qualquer posicionamento explícito em favor de uma ou outra escola. Sob a influência da organização industrial, os estudos setoriais são frequentes.

Ainda durante a década de 1980, temáticas que, nos dias de hoje, são consideradas relevantes e com- põem agendas de pesquisa atuais, como inovação, responsabilidade social empresarial e gestão de empresas familiares e de pequeno porte, são objeto de análise, inclusive por meio da introdução de fóruns de discussão especializados. Nota-se crescente preocupação com o uso de teoria ou, ao menos, com o posicionamento dos trabalhos em termos de aporte conceitual. Contudo, na produção de toda a década de 1980, encontram-se textos com seguidos parágrafos que não citam referências, direta ou indiretamente, ao discutirem conceitos. Há uma característica fortemente prescritiva em grande parte dos textos, sobretudo naqueles que apresentam ferramentas de gestão desenvolvidas em contextos de países desenvolvidos. Nessa década, grande parte dos artigos ainda é de autores que aparentam comprometimento com a exposição de conteúdo de suporte à gestão profissional, sem necessariamente buscar avanço substantivo do conhecimento teórico em seus campos de atuação. Predominam, no período, trabalhos ensaísticos e/ou de discussão teórica, embora haja notável incidência de análises empíricas. A explicitação do método não parece ser obrigatória para a publicação, embora vários trabalhos apresentem uma seção de método e demonstrem valorizá-lo para garantir qualidade e transparência das análises, mesmo sem os padrões de rigor que seriam necessários nos dias de hoje. Embora raros, há trabalhos pioneiros que empregam técnicas de análise que hoje podem ser consideradas desafiadoras, como a análise fatorial e o estudo de caso.

Antecipando algumas das muitas mudanças pelas quais a revista passaria a partir da década seguinte, o estilo de escrita altera-se na segunda metade de década de 1980, em oposição à primeira metade, quando os temas se apresentavam de maneira direta. Na segunda metade, há introduções que contextualizam os trabalhos em termos dos desafios pertinentes à época. Alguns trabalhos reproduzem o estilo emergente em muitos periódicos internacionais da área de economia, com uso de equações formais que se propõem a explicar o comportamento das pessoas, dos mercados e das sociedades. Apenas ao final dessa década é que a revista passa a incluir resumo e palavras-chave em seus artigos. Autores de prestígio e atuação destacada na FGV-EAESP continuam a contribuir com a revista, como Fernando Prestes Motta, Raimar Richers, Claude Machline (autor do primeiro artigo publicado na história do periódico), Carlos Osmar Bertero e Luiz Carlos Bresser-Pereira.

A segunda fase da produção bibliográfica nas instituições de ensino em administração no Brasil 
iniciou-se na segunda metade dos anos 1990, como reflexo do aprofundamento do processo normatizador que fomentava a pós-graduação para transformá-la em provedora de pesquisadores. A Capes foi criada em 1951 com a missão de incentivar e regulamentar a formação de profissionais pelo ensino superior, inclusive com intuito de ampliar a quantidade de profissionais pós-graduados (com mestrados e doutoramentos) que pudessem atuar como docentes no próprio ensino superior. Segundo Bertero (2006), foi no final da década de 1990 que a Capes começou a aplicar à área de Administração os critérios de avaliação dos cursos de stricto sensu. O processo deu-se por meio da introdução de controles e incentivos, resultando no fortalecimento das linhas de pesquisa e no redirecionamento dos programas. Nessa década, a Anpad havia sido consolidada e promovia inovações importantes: a organização dos encontros anuais foi profissionalizada, instituiu-se o blind review à avaliação dos trabalhos, enquanto o número de submissões ao Enanpad cresceu de 193, em 1990, a 1.300, em 2000. O resultado foi o aumento sensível da produção acadêmica brasileira em termos quantitativos (BERTERO, CALDAS, WOOD JR, 2005; FACHIN, 2006).

A década de 1990 foi decisiva para que a $R A E$ se tornasse a revista que conhecemos hoje. Nessa década, os artigos com ênfase em desenvolvimento econômico e na administração pública tornaram-se mais raros. Foi também nessa época que a $R A E$ consolidou-se definitivamente como publicação voltada ao management, dada a ênfase a temáticas referentes aos desafios da gestão no setor privado. Entre tais desafios, destacamse os assuntos relacionados ao trabalho e seu sentido, à gestão de carreiras e à inserção e à adaptação de indivíduos e grupos às organizações. Estudos críticos, em seu sentido mais flexível, começaram a aparecer com mais frequência. Concomitantemente, discussões envolvendo aplicações e implantações de ferramentas e modelos gerenciais nas áreas de marketing, finanças corporativas, contabilidade de custos, tecnologia da informação e produção também caracterizaram o período.

Na década de 1990, a $R A E$ não dialogava mais prioritariamente com profissionais não acadêmicos e buscava contribuir com o processo de reformulação da pós-graduação como produtora de pesquisa. Não que a revista já apresentasse plenamente as características que hoje definimos como determinantes de um periódico estritamente acadêmico, mas esforços de formação e consolidação de uma academia de pesquisadores brasileiros em administração se ob- servam. Apareceram os primeiros textos com balanços e críticas sobre a produção acadêmica nacional, com ênfase no debate sobre temáticas e aspectos teórico-metodológicos. Os debates envolvendo o uso de abordagens específicas na análise organizacional e da estratégia empresarial, como o paradigma da complexidade ou a ecologia populacional, foram inseridos na produção da década. A $R A E$, assim, ensaiava a aproximação do formato apresentado por periódicos internacionais de prestígio (VALENTE e SERAFIM, 2006).

Nessa década de transição, as transformações experimentadas pela $R A E$ levaram-na a reposicionar-se e assumir seu papel como publicação para professores pesquisadores. Por outro lado, a revista identificavase simultaneamente com dois públicos, acadêmicos e praticantes, o que levou à sua segmentação (VALENTE e SERAFIM, 2006). A RAE-light (cujo conteúdo não foi analisado neste estudo) surgiu como um suplemento da revista, incorporada à $R A E$ pouco tempo depois, e empregava comunicação e conteúdo mais adequados ao diálogo com os praticantes, naquele momento parcialmente alijados dos debates da academia e estranhos à forma com que os pesquisadores passaram a se expressar (VALENTE e SERAFIM, 2006). Contudo, até o final da década, ainda havia quantidade limitada de trabalhos com análises empíricas, e as incursões metodológicas estavam longe da sofisticação que se observa hoje. Algum estilo ensaístico de livre-pensar textual ainda podia ser observado em muitos trabalhos, e a $R A E$ parecia incorporar uma vocação dupla ao conversar com acadêmicos e praticantes por meio de linguagens e objetos simultaneamente distintos, mesmo com a tendência crescente de privilegiar o diálogo com o público acadêmico, o que se aprofundaria na década seguinte.

No final da década de 1990, os incentivos à produção científica nacional levaram nossos canais de divulgação da produção bibliográfica à adoção de critérios mais acadêmicos para que um artigo avançasse nos processos editoriais, abrangendo a apreciação de seu rigor e relevância. Na $R A E$, esse processo acelerou-se na década de 2000, quando o Prof. Thomaz Wood assumiu a direção da revista para tornála "uma revista acadêmica no padrão internacional" (VALENTE e SERAFIM, 2006, p. 110). Nesse período, o modus operandi da pesquisa acadêmica tornavase condição à publicação, como regulamentado pela Capes, induzindo mudanças amplas nos periódicos publicados pelas escolas de negócios, restringindo o que seria, a partir de então, publicado. Argumentamos 
que tal processo caracterizou-se pela ênfase crescente no rigor científico, que passava a ser exigido dos manuscritos, implicando principalmente a construção teórica e conceitual cuidadosa e a observância a ditames metodológicos.

Na década de 2000, a $R A E$ deu continuidade à trajetória priorizada ao final da década anterior. No ano de 2002, a revista passou a publicar, ao final de cada artigo, a data de submissão e aprovação, em consonância ao processo de revisão duplo-cega, marca dos processos de avaliação de trabalhos acadêmicos da atualidade. Essas informações passariam a ser exigidas pela Capes a partir de 2008. Na segunda metade da década de 2000 , a $R A E$ já se tornara uma publicação destinada ao meio acadêmico, com produção bem delimitada em termos de abordagens teóricas oriundas da academia internacional, principalmente a norte-americana. Os métodos também assumem maior rigor, sendo comumente mencionados nos títulos dos trabalhos, junto às lentes epistemológicas adotadas. Os avanços metodológicos manifestam-se por meio de técnicas qualitativas, como a análise de conteúdo em estudos de casos, ou quantitativas, como a modelagem por equações estruturais. Predominam agora os trabalhos teórico-empíricos, que dialogam com teorias dominantes, enquanto temas como sustentabilidade, inovação, internacionalização de negócios e responsabilidade social tornam-se mais frequentes.

Havendo incentivos institucionais para a diversificação do corpo editorial e do quadro de autores e avaliadores em termos regionais, o conteúdo da $R A E$ é, atualmente, provido pelos núcleos acadêmicos das escolas de negócios do país. A produção analisada da $R A E$ demonstra evolução em termos de rigor metodológico. Como consequência, os resultados apresentados nas pesquisas tornaram-se mais confiáveis, com reflexões menos arriscadas. A pesquisa está mais ancorada no conhecimento acumulado. No entanto, sua flexibilidade está reduzida, pois sua comunicação está limitada a formas de expressão dominadas basicamente por pesquisadores, e seus objetos de análise limitamse àqueles em que é possível empregar o padrão de rigor metodológico exigido pela academia no que se refere a procedimentos como amostragem, acesso a dados e critérios de análise, entre outros. A própria sofisticação dos métodos desafia a expectativa de que sejam compreendidos por não pesquisadores. Ademais, as conclusões e discussões gerenciais são geralmente tímidas, por conta de riscos que o pesquisador não quer assumir. Por exemplo, os autores têm indicado que seus achados sugerem certas considerações mais do que têm se comprometido com conclusões definitivas, adotando discurso pouco direto em termos de como seus trabalhos poderiam auxiliar a tomada de decisão, além de darem maior enfoque às implicações teóricas de seus estudos do que às gerenciais. Enquanto a revista tornava-se ferramenta fundamental à evolução da rede de pesquisadores, sua linguagem e o formato da comunicação científica impuseram obstáculos ao seu consumo pelos praticantes da administração (não pesquisadores).

\section{DISCUSSÃO: 0 DESAFIO DE CONSTRUIR A RELEVÂNCIA DE NOSSA PESQUISA}

A análise da trajetória da $R A E$ revela uma inflexão importante: de uma revista científica que refletiria o pensamento da EAESP, direcionada à classe emergente dos administradores brasileiros carentes de conhecimento especializado e relevante a uma ferramenta essencial ao debate e à divulgação científica, agora já no círculo especializado dos pesquisadores em administração. Essa inflexão caracterizou-se, também, pela implantação progressiva de critérios e procedimentos acadêmicos e científicos, e pela ênfase crescente no rigor teórico-metodológico. A questão da relevância e do impacto do conhecimento produzido, porém, sugere reflexões importantes à comunidade científica.

Não são recentes as críticas à falta de relevância da produção científica nacional em administração. Para diversos autores, os problemas de qualidade e originalidade de nossa pesquisa estariam relacionados a aspectos institucionais e culturais (ROESCH, 2003; RODRIGUES, 2004; ROESCH, 2004; CARVALHO e VIEIRA, 2003a; CARVALHO e VIEIRA, 2003b; SERRA, FIATES, FERREIRA, 2008; MATTOS, 2008). Entre eles, está o próprio fato de que a produção acadêmica nacional tende a mimetizar o que é produzido nos Estados Unidos (BERTERO e KEINERT, 1994; VERGARA E PINTO, 2001; RODRIGUES e CARRIERI, 2001). Nesse sentido, um objetivo legítimo de nossa comunidade seria consolidar comprometimentos não somente com rigor teórico-metodológico, mas também com a produção de conhecimento relevante, por estar atrelado às necessidades de nossa sociedade em transformação, refletindo nossas particularidades socioculturais. 
O debate em torno da relevância do conhecimento científico em administração é global com condicionantes locais. Nos Estados Unidos, por exemplo, diversos estudos colocam em destaque a distância entre teoria e prática em recursos humanos, revelando dois mundos separados, o do acadêmico e o do praticante (RYNES, COLBERT, BROWN, 2002; RYNES, GILUK, BROWN, 2007; DEADRICK e GIBSON, 2007; DEADRICK e GIBSON, 2009). A possibilidade de que os gestores ignorem a produção científica das escolas de administração possui implicações importantes e controversas à evolução do sistema de ensino e pesquisa em administração. Se o conteúdo que produzimos e disseminamos é ignorado, por que o fazemos? Para que serviria a produção de conhecimento científico em administração, senão para munir os praticantes? Essas reflexões podem levar-nos a produzir críticas sobre o que se faz nas escolas de negócios, tais como as formuladas por Mintzberg (2004), segundo a qual os conteúdos dos programas de $M B A$ não teriam qualquer relevância para os gestores.

Em um cenário em que a educação em administração se desenvolveu tradicionalmente em consonância com a necessidade de se habilitarem profissionais para a gestão, a possibilidade de o conhecimento produzido nas escolas não ter relevância aos praticantes é desconfortável. A análise aqui feita pode sugerir, porém, que o conhecimento é ignorado pelos gestores justamente pelo fato de que não tem sido produzido para os gestores. Ao privilegiarmos o rigor de nossa produção em detrimento do seu impacto entre praticantes, estaríamos direcionando-a a uma audiência especializada de pesquisadores e afastando-a dos gestores. Nesse sentido, seria possível dizer que são as escolas de negócios que, em parte, ignoram os praticantes.

Diante dessas críticas possíveis, cabe-nos discutir a dinâmica de nossa comunidade em busca de questões para reflexão. O debate sobre a qualidade de nossa produção fornece-nos várias pistas, enfatizando não somente os condicionantes culturais e institucionais aos quais estamos submetidos, mas também as estratégias de ação dos programas e dos pesquisadores (RODRIGUES, 2004; ROSSONI e GUARIDOFILHO, 2009; KIRSCHBAUM e MASCARENHAS, 2009). Por exemplo, Mattos (2008) e Rosa (2008) analisam o sistema Capes de avaliação da pós-graduação, discutindo práticas de pesquisa e suas repercussões à nossa produção. Em tal contexto institucional, a pressão por publicação estimularia várias inversões, tais como a preponderância da definição do método so- bre a formulação sofisticada e original de problemas de pesquisa, a submissão dos projetos acadêmicos às demandas inadiáveis de produtividade na carreira e a "demissão da identidade", ou o fenômeno de os pesquisadores e programas abdicarem da construção de identidades acadêmicas próprias, enfatizando a produção industrial de textos em detrimento da produção criativa e relevante.

Assim, a regra do "quanto mais, melhor" subverteria a lógica acadêmica da ênfase em impacto, relevância e originalidade (MATTOS, 2008; CARVALHO e VIEIRA, 2003b). Por outro lado, estariam os pesquisadores cientes de que "a qualidade de seu trabalho tem uma referência pessoal básica relativa ao seu amadurecimento progressivo na carreira?" (MATTOS, 2008, p. 148). Entre as manifestações do fenômeno de "demissão da identidade" descrito, faltaria aos nossos estudos o rigor metodológico e a maturação das ideias (BERTERO, 2003; ROESCH, 2003; RODRIGUES, 2004; BERTERO, 2007). Essas provocações convidamnos a refletir sobre nossas práticas e prioridades em pesquisa e, em especial, às questões de como construir rigor e relevância de nossa produção apesar das pressões impostas pelo "publicar ou perecer". Dois momentos do trabalho científico parecem ser particularmente importantes.

Em primeiro lugar, se a relevância de um texto científico diz respeito ao consenso social em torno da importância e pertinência dos problemas tratados, seriam críticas as nossas práticas de priorização, definição e caracterização de perguntas e abordagens de pesquisa. Quem atribui a um trabalho sua relevância são os membros de uma comunidade, pois o texto deve dialogar com suas predisposições, provando-se útil à (re)definição de suas realidades. Esses diálogos exigiriam o comprometimento dos pesquisadores. Sobre tal comprometimento, Mattos (2008, p. 146) sugere que a relevância "surge de outros contextos qualitativos e se promove, sobretudo, por exposição de uma comunidade de praticantes de pesquisa a outras, e a outros setores da vida social". Assim, um problema de pesquisa deveria surgir mediante um diálogo com stakeholders, por meio do qual o fenômeno a ser estudado se estabelece e se caracteriza, e sua relevância é avaliada (VAN DE VEN, 2007).

Em segundo lugar, a contextualização e a tradução das reflexões geradas no âmbito de nossos processos acadêmicos permitem maior alcance da pesquisa em administração. Trata-se, contudo, de um esforço desprestigiado em nosso esquema atual 
de carreira (VAN DE VEN, 2007). A variante mais comum desse tipo de comprometimento é a seção de implicações à prática, cuja pertinência merece maior atenção. Por exemplo, Doh (2010) questiona se as "implicações à prática" seriam somente uma espécie de posfácio ou nossa contribuição principal. Ou se as implicações à prática seriam de fato úteis aos praticantes, pois expressariam as concepções que os cientistas lhes imputam (KIESER e LEINER, 2009). Ou, ainda, se algum estudo em si teria implicações consistentes à prática, já que a síntese de um corpo de evidências científicas seria o primeiro passo ao seu uso efetivo, abrangendo acúmulo, análise e interpretação de um corpo de evidências empíricas (ROUSSEAU, MANNING, DENYER, 2008). Essas críticas possíveis revelam a complexidade do debate.

Situar, definir, contextualizar problemas e traduzir achados seriam atividades críticas e dependentes de diálogo entre pesquisador, pesquisados, praticantes e especialistas de diversas áreas que, munidos de suas perspectivas variadas, seriam capazes de iluminar a problemática, tornando-a significativa. Aprimorar esses diálogos desde a concepção das iniciativas de pesquisa até sua conclusão e divulgação, em meio a relacionamentos de mão dupla e por comunicação engajada, pode valorizar a contribuição dos textos que publicamos nos periódicos especializados, alavancando seu potencial transformador

Reconhecemos as dificuldades práticas inerentes a essa posição de diálogo, que vem gerando debates produtivos (VAN DE VEN e JOHNSON, 2006; BARTUNEK, 2007; WEICK, 1996; GULATI, 2007; SHANI e outros, 2008; JARZABKOWSKI, MOHRMAN, SCHERER, 2010; KIESER e LEINER, 2009). Construir a relevância da pesquisa acadêmica por meio da diminuição da lacuna entre a pesquisa e a prática vem sendo um objetivo controverso, e um debate que enseja argumentos conflitantes (por exemplo, ver discussão entre STARKEY e MADAN, 2001, e GREY, 2001). Porém, acreditamos que reconhecer tais argumentos pode revelar limitações importantes de nosso fazer ciência. Além disso, apesar de não querer desejar necessariamente sua preponderância, tal visão da pesquisa aplicada daria ensejo a práticas capazes de fazer dialogar predisposições frequentemente díspares, viabilizando maior integração entre comunidades distintas, facilitando a comunicação e as transferências de conhecimento.

Apesar de a essência de nosso saber fazer estar relacionada às questões cotidianas da gestão, a atividade acadêmica é distinta e distanciada da vida organizacional (JARZABKOWSKI, MOHRMAN, SCHERER, 2010). Por mais que colecionemos contatos nas organizações, estes nos servem somente, sem que nos engajemos em relacionamentos consistentes de mão dupla, até porque a transferência de conhecimentos não é processo trivial. Entre as consequências, rigor e relevância não andariam juntos, mas estariam inadequadamente em posições opostas em um pêndulo, forjando comunidades fechadas em si e calcadas em uma falsa polarização segundo a qual a pesquisa feita com rigor perderia em apelo prático, em "vida", tornando-se mais restrita, incremental, mais distante do mundo real, enquanto a pesquisa feita com os olhos nos praticantes teria baixa qualidade (GULATI, 2007; GHOSHAL, 2005). Enquanto perpetuarmos tal polarização, estaremos em eterna desvantagem em relação a consultores e jornalistas, mais adaptados à linguagem, às prioridades e ao ritmo dos gestores e, talvez por isso, mais aptos a impactar no dia a dia da administração.

\section{NOTA DE AGRADECIMENTO}

Os autores agradecem os professores Carlos Osmar Bertero, Flávio Carvalho de Vasconcelos, Luis Enrique Urtubey De Césaris e Eduardo Diniz pelo apoio à pesquisa e à elaboração do texto, e também aos assistentes de pesquisa Rogério Morano, Carla Caruso, Silvia Morais e Michelli Bruno por sua participação no estudo de caso. 


\section{REFERÊNCIAS}

ALMEIDA JUNIOR, A. e outros. Parecer CFE no 977/65, aprovado em 3 dez. 1965. Revista Brasileira de Educação, Rio de Janeiro, n. 30, 2005. Disponível em: http://www.scielo.br/scielo.php?script=sci_ arttext\&pid=S1413-24782005000300014\&lng=en\&nrm =iso. Acesso em 11.05.2011.

BARTUNEK, J. Academic-practitioner collaboration need not require joint or relevant research: toward a relational scholarship of integration. Academy of Management Journal, v. 50, n. 6, p. 1323-1333, 2007.

BEECH, N; MACINTOSH, R; MACLEAN, D. Dialogues between academics and practitioners: the role of generative dialogic encounters. Organization Studies, v. 31, n. 9\&10, p. 1341-1367, 2010.

BERTERO, C. O. Comentando. Organizações e Sociedade, v. 10, n. 26, p. 189-190, 2003.

BERTERO, C. O. Ensino e Pesquisa em Administração. São Paulo: Thompson. 2006. 135 p.

BERTERO, C. O. Editorial. RAE-eletrônica, v. 6, n. 1, 2007. Disponível em http://rae.fgv.br/rae-eletronica/ vol6-num1-2007. Acesso em 11.05.2011.

BERTERO, C; CALDAS, M; WOOD JR. Produção científica em administração de empresas: provocações, insinuações e contribuições para um debate local. Revista de Administração Contemporânea, v. 2, n. 1, p. $147-178,1999$.

BERTERO, C; CALDAS, M; WOOD JR. Produção científica em administração no Brasil: o estado da arte. São Paulo: Atlas, 2005.

BERTERO, C. O; KEINERT, T. M. M. A evolução da análise organizacional no Brasil (1961-93). RAE-revista de administração de empresas, v. 34, n. 3, p. 81-90, 1994.

BOUZAN, A. O administrador de empresas no desenvolvimento do Brasil. RAE-revista de administração de empresas, v. 6, n. 19, p. 41-58, 1966.

BRESSER-PEREIRA, L. C. Desenvolvimento e crise no Brasil 1930-1983. 17. ed. São Paulo: Brasiliense, 1994.
CARVALHO, C; VIEIRA, M. Algo está podre no reino da Dinamarca. Organizações e Sociedade, v. 10, n. 26, p. $185-187,2003$ a.

CARVALHO, C; VIEIRA, M. Tréplica ao professor Bertero. Organizações e Sociedade, v. 10, n. 27, p. 179180, 2003b.

CLARK, T; FLOYD, S; WRIGHT, M. On the review process and journal development. Journal of Management Studies, v. 43, n. 3, p. 655-663, 2006.

DEADRICK, D; GIBSON, P. An examination of the research-practice gap in HR: comparing topics of interest to HR academics and HR professionals. Human Resource Management Review, v. 17, n. 2, p. 131-139, 2007.

DEADRICK, D; GIBSON, P. Revisiting the researchpractice gap in HR: a longitudinal analysis. Human Resource Management Review, 19, n. 1, p. 144-153, 2009.

DOH, J. Introduction: implications for practice - core contribution or afterthought? Academy of Management Learning and Education, v. 9, n. 1, p. 98-99, 2010.

EISENHARDT, K. Better stories and better constructs: the case for rigor and comparative logic. Academy of Management Review, v. 16, n. 3, p. 620-627, 1991.

FACHIN, R. C. Construindo uma associação científica: trinta anos da Anpad - memórias, registros, desafios. Porto Alegre: Anpad. 2006. 242 p.

FREITAS, A. G. Introdução às teorias administrativas. Campinas: Alínea, 1998.

GHOSHAL, S. Bad management theories are destroying good management practices. Academy of Management Learning E Education, 4, n. 1, p. 75-91, 2005.

GIBBONS, M; LIMOGES, H; NOWOTNY, H; SCHWARTZMAN, S; SCOTT, P; TROW, M. The new production of knowledge: the dynamics of science and research in contemporary societies. London: Sage, 1994.

GOLDEN-BIDDLE, K; LOCKE, K. Appealing work: an investigation of how ethnographic texts convince. Organization Science, v. 4, n. 4, p. 595-616, 1993. 
GREY, C. Re-imagining relevance: a response to starkey and madan. British Journal of Management, v. 12, n. 1, p. S27-S32, 2001.

GULATI, R. Tent poles, tribalism, and boundary spanning: the rigor-relevance debate in management research. Academy of Management Journal, v. 50, n. 4, p. 775-782, 2007.

GVEXECUTIVO. A RAE nos seus 50 anos. GVexecutivo, v. 10, n. 1, p. 66-67, 2011.

HUFF, A; HUFF, J. Refocusing the business school agenda. British Journal of Management, v. 12, n. 1, p. S49-S54, 2001.

JARZABKOWSKI, P; MOHRMAN, S; SCHERER, A. Organization studies as applied science: the generation and use of academic knowledge about organizations - introduction to the special edition. Editorial. Organization Studies, v. 31, n. 9\&10, p. 1189-1207, 2010.

KIESER, A; LEINER, L. Why the rigor-relevance gap in management research is unbridgeable? Journal of Management Studies, v. 46, n. 3, p. 516-533, 2009.

KIRSCHBAUM, C; MASCARENHAS, A. Nos limites da autonomia: reflexões sobre práticas de blind review e editoria de revistas científicas em administração no Brasil. RAE-eletrônica, v. 8, n. 1, p. 12, 2009. Disponivel em http://rae.fgv.br/rae-eletronica/ vol8-num1-2009/nos-limites-autonomia-reflexoessobre-modelo-brasileiro-blind-review. Acesso em 11.05.2011.

KNIGHTS, D; SCARBROUGH, H. In search of relevance: perspectives on the contribution of academic-practitioner networks. Organization Studies, v. 31, n. 9\&10, p. 1287-1309, 2010.

MACHADO-DA-SILVA, C; GUARIDO-FILHO, E; ROSSONI, L; GRAEFF, J. Periódicos brasileiros de administração: análise bibliométrica de impacto no triênio 2005-2007. RAC-Eletrônica, v. 2, n. 3, p. 351-373, 2008.

MATTOS, P. Nós e os índices: a propósito da pressão institucional por publicação. RAE-revista de administração de empresas, v. 48, n. 2, p. 144149, 2008.
MINTZBERG, H. Managers, not MBAs: a hard look at the soft practice of managing and management development. San Francico, CA: Berrett-Koehler, 2004. $464 \mathrm{p}$.

NICOLAI, A; SEIDL, D. That's relevant! Different forms of practical relevance in management science. Organization Studies, v. 31, n. 9\&10, p. 1257-1285, 2010.

PFEFFER, J; FONG, C. T. The end of business schools? Less success than meets the eye. Academy of Management Learning \& Education, v. 1, n. 1, p. 78-96, 2002.

PINHO, J. A. G. D. Brevíssimo manual do editor: considerações sobre submissão e avaliação de artigos, o papel dos pareceristas e do editor de revistas científicas. Organizações e Sociedade, v. 12, n. 34, p. 169-173, 2005.

RODRIGUES, S. B. Quem responde pelo desempenho limitado da produção científica em administração no Brasil. Organizações e Sociedade, v. 11, n. 29, p. 193196, 2004.

RODRIGUES, S; CARRIERI, A. A tradição anglosaxônica em estudos organizacionais brasileiros. Revista de Administração Contemporânea, v. 5, ed. especial, p. 81-102, 2001.

ROESCH, S. M. A. Quem responde pelo desempenho limitado da produção científica em administração no Brasil. Organizações e Sociedade, v. 10, n. 28, p. 165167, 2003.

ROESCH, S. M. A. Tréplica à Suzana Rodrigues. Organizaçôes e Sociedade, v. 11, n. 29, p. 197-197, 2004.

ROSA, A. "Nós e os índices": um outro olhar sobre a pressão institucional por publicação. RAE-revista de administração de empresas, v. 48, n. 4, p. 108-114, 2008.

ROSSONI, L; GUARIDO-FILHO, E. Cooperação entre programas de pós-graduação em administração no Brasil: evidências estruturais em quatro áreas temáticas. Revista de Administração Contemporânea, v. 13, n. 3, p. 366-390, 2009.

ROUSSEAU, D; MANNING, J; DENYER, D. Evidence in management and organizational science: assembling the field's full weight of scientific knowledge through syntheses. AIM Working Paper Series: 067, 
2008. Disponível em: http://www.evidencebasedmanagement.com/wp-content/uploads/2010/01/ ROUSSEAU-Evidence_2_15_08-11.pdf. Acesso em 23.03.2011.

RYNES, S. Editor's afterword: let's create a tipping point - what academics and practitioners can do, alone and together. Academy of Management Journal, v. 50, n. 5, p. 1046-1054, 2007.

RYNES, S; BARTUNEK, J; DAFT, R. Across the great divide: knowledge creation and transfer between practitioners and academics. Academy of Management Journal, v. 44, n. 1, p. 340-355, 2001.

RYNES, S; COLBERT, A; BROWN, K. HR professional beliefs about effective human resource practices, correspondence between research and practice. Human Resource Management, v. 41, n. 2, p. 149-174, 2002.

RYNES, S; GILUK, T; BROWN, K. The very separate worlds of academic and practitioner periodicals in human resource management: implications for evidencebased management. Academy of Management Journal, v. 50, n. 5, p. 987-1008, 2007.

SERRA, F; FIATES, G; FERREIRA, M. Publicar é difícil ou faltam competências? O desafio de pesquisar e publicar em revistas científicas na visão de editores e revisores internacionais. Revista de Administração Mackenzie, v. 9, n. 4, ed. especial, p. 32-55, 2008.

SHANI, A; ADLER, N; MOHRMAN, S; PASMORE, W; STYMNE, B. (Eds) Handbook of collaborative management research. Thousand Oaks: Sage, 2008.

SILVA, G. S. Administração de empresas e desenvolvimento. RAE-revista de administração de empresas, v. 11, n. 3, p. 5-20, 1971.

SOUZA, J. C. P. Roberto Saboia de Medeiros, S. J.: apóstolo da ação social. São Paulo: Loyola, 1980.

STARKEY, K; MADAN, P. Bridging the relevance gap: aligning stakeholders in the future of management research. British Journal of Management, v. 12, n.1, p. S3-S26, 2001.

SWAN, J; BRESNEN, M; ROBERTSON, M; NEWELL, S; DOPSON, S. When policy meets practice: colli- ding logics and the challenges of 'mode 2' initiatives in the translation of academic knowledge. Organization Studies, v. 31, n. 9\&10, p. 1311-1340, 2010.

TONELLI, M; CALDAS, M; LACOMBE, B; TINOCO, T. Produção acadêmica em recursos humanos no Brasil: 1991-2000. RAE-revista de administração de empresas, v. 43, n. 1, p. 105-122, 2003.

VALENTE, R; SERAFIM, M. RAE 45 anos: recortes de sua história. RAE-revista de administração de empresas, v. 46, n. 2, p. 104-111, 2006.

VAN DE VEN, A. Engaged scholarship: a guide for organizational and social research. Oxford: Oxford University Press, 2007.

VAN DE VEN, A; JOHNSON, P. Knowledge for theory and practice. Academy of Management Review, v. 31, n. 4, p. 802-821, 2006.

VASCONCELOS, F. Relevância e rigor na academia. Editorial. RAE-revista de administração de empresas. v. 49, n. 1, p. 5, 2009.

VERGARA, S; PINTO, M. Referências teóricas em análise organizacional: um estudo das nacionalidades dos autores referenciados na literatura brasileira. Revista de Administração Contemporânea, v. 5, n. 2, p. 103121, 2001.

WEICK, K. Speaking to practice: the scholarship of integration. Journal of Management Inquiry, v. 5, n.1, p. 251-258, 1996. 